\title{
RESISTIR NA (RE) EXISTÊNCIA: DECOLONIZANDO SABERES NA RELAÇÃO UNIVERSIDADE-ESCOLA-COMUNIDADE
}

\author{
Cora Elena Gonzalo Zambrano \\ Marina Reinoldes \\ Karlla Andrea Leal Cruz
}

\begin{abstract}
RESUMO: o objetivo deste texto é problematizar a relação universidade-escola-comunidade, incentivando o desenvolvimento do potencial profissional e humano de discentes e docentes nos três pilares: ensino, pesquisa e extensão. Nesse viés, destacamos ainda, a relação dialógica (CALVO E FREITAS, 2011) e decolonial dos saberes (MIGNOLO, 2013; QUIJANO, 2005) de todos os entes envolvidos. Com uma abordagem qualitativa e interpretativista, por meio de pesquisa bibliográfica e relatos de experiência das pesquisadoras em três instituições de ensino superior: UFMG, UNIFESP e UERR. As discussões nos guiam para uma transformação do sujeito da educação em presença, seguindo Biesta (2017). Assim, ressaltamos a visão teórica como movimento que prescinde da prática, cuja prática ressignifica a teoria, através da noção de dialogicidade que caminha para a (re)construção de uma universidade como agência, que resiste e (re)existe com a escola e com a sociedade.
\end{abstract}

PALAVRAS-CHAVE: Ensino-pesquisa-extensão. Dialogicidade. Decolonialidade. (Re) existência.

\section{CONSIDERAÇões INICIAIS}

"Não posso ser professor se não percebo cada vez melhor que, por não ser neutra, minha prática exige de mim uma definição. Uma tomada de posição. Decisão. Ruptura. Exige de mim que escolha entre isto e aquilo.... contra qualquer forma de discriminação, contra a dominação econômica dos indivíduos ou das classes sociais. Sou professor contra a ordem capitalista vigente que inventou esta aberração: a miséria na fartura. Sou professor a favor da esperança que me anima apesar de tudo." (FREIRE, 1996, p.115)

Em um cenário em que os cortes nas bolsas de pesquisas, na redução dos orçamentos que impactam diretamente o funcionamento mínimo da instituição - como o cumprimento das obrigações com gastos de luz, água e pagamento de funcionários terceirizados - e outras ações vinculadas diretamente ao projeto político de desmonte da universidade pública e de silenciamento do pensamento crítico, se faz necessário repensar o papel das universidades e suas relações com a escola e a sociedade.

Uma vez que as instituições públicas de ensino superior são sustentadas pelos pilares da indissociabilidade entre ensino, pesquisa e extensão, o diálogo com outros agentes e saberes e o conceito de uma universidade socialmente referenciada precisam, mais do que nunca, saírem do papel e serem colocadas em práticas. O fortalecimento desse diálogo é apenas uma das possibilidades concretas de enfrentamento ao sucateamento do ensino superior, ao mesmo tempo em que atua, também, como um processo de conscientização da sociedade em relação à apropriação da universidade pública como um espaço que lhe é de direito.

Não nos propomos, a partir deste texto, responder ou encontrar uma resposta definitiva para fortalecer o vínculo entre universidade-escola-comunidade. Não obstante, compartilhamos algumas reflexões, de forma despretensiosa, sobre possibilidades de parceria e inquietações sobre essa linha tênue que, se por um lado aproxima a universidade desse diálogo, do outro reflete o quão frágil e vulnerável seguem essas parcerias, apesar de alguns avanços apresentados por Reis et al (2019).

Levando em consideração que a formação docente está permeada por relações de poder, nosso objetivo é problematizar a relação universidade-escola-comunidade, incentivando o desenvolvimento do potencial profissional e humano de discentes e docentes nos três pilares: ensino, 
pesquisa e extensão. Nesse viés, destacamos ainda, a relação dialógica (CALVO E FREITAS, 2011) e decolonial dos saberes (MIGNOLO, 2018) de todos os entes envolvidos.

O presente artigo, portanto, está inserido na área de Linguística Aplicada Transgressiva e Indisciplinar ${ }^{1}$ (MOITA LOPES, 2006; PENNYCOOK, 2006), cuja perspectiva tem em sua agenda, de acordo com Kleiman (2013. P. 41), romper com "o monopólio do saber das universidades e outras instituições que reúnem grupos de pesquisadores e intelectuais". A autora faz uma discussão entre centro e periferia na produção do conhecimento e defende a construção de currículos que permitam a valorização de saberes por grupos periféricos (em relação aos centros hegemônicos), ao passo que reconhecem os saberes por eles produzidos. Dessa forma, Kleiman $(2013,53)$ ressalta a resistência ou reexistência de grupos minorizados como, por exemplo, indígenas e comunidades ribeirinhas que, "a partir da periferia, produzem novos saberes num processo de transformação do global pelo local".

A abordagem metodológica neste trabalho é qualitativa e interpretativista (BORTONI-RICARDO, 2008), com pesquisa bibliográfica e relato de experiências das pesquisadoras. Durante as discussões e reflexões, portanto, apresentamos algumas iniciativas da Universidade Federal de São Paulo (UNIFESP), Universidade Estadual de Roraima (UERR) e Universidade Federal de Minas Gerais (UFMG) que, em alguma medida, dialogam diretamente com outros setores e agentes da sociedade.

Na primeira parte do artigo apresentamos algumas reflexões acerca da instituição escolar; posteriormente, debatemos a relação entre universidade e escola; na sequência, uma das pesquisadoras apresenta projetos da UFMG que conseguiram unir as duas instituições. Na seção seguinte, a discussão versa sobre a relação entre universidade e comunidade, por meio dos projetos de extensão universitária; em seguida, apresentamos um projeto da UNIFESP que surgiu por iniciativa de um grupo de discentes da instituição com o intuito de atender uma demanda social, traçando a relação entre os três pilares universitários. Por último, explanamos acerca de um projeto de extensão oferecido pela UERR, na fronteira entre o Brasil e a Venezuela.

\section{A instituição escolar}

Apesar do aumento nos índices de universalização do acesso à educação básica, de acordo com o Anuário Brasileiro de Educação Básica 2019, o modus operandi da escola, sobretudo da sala de aula e da rotina escolar, ainda apresenta algumas semelhanças com o sistema escolar do século XIX: carteiras individuais, enfileiradas - com o intuito de promover um maior controle do professor sobre os alunos - o quadro grande na frente da sala, os horários definidos para entrada e saída, o controle do corpo discente na sala de aula e a vigilância (ARRIADA et al 2012), por exemplo.

Com relação à organização escolar, Street (2014) apresenta a escola como uma instituição que defende a superioridade, o controle e a dominação, também através desse mecanismo organizacional dos espaços e horários, o que o autor chama de letramento autônomo ${ }^{2}$ de localização e organização.

1 Inserido nessa área, há um estudo proposto pela professora Ana Lúcia Silva Souza, "Letramentos de Reexistência", cujas práticas nos são muito caras e que gostaríamos de indicar para leitura.

2 É um modelo de letramento no qual o indivíduo adquire as práticas de leitura e escrita dissociadas do contexto sócio-histórico, limitado aos contextos escolares e de forma passiva. 
Algumas escolas públicas brasileiras expressam essa vigilância e autoritarismo na própria estrutura do espaço escolar, cercado de cadeados, portas fechadas e grades. A escola deixa, então, de ser um espaço alegre e torna-se uma espécie de serviço militar obrigatório aos 7 anos de idade, como problematiza o antropólogo e educador popular Tião Rocha ${ }^{3}$ (2014). É preciso pensar, então, que tipo de memória afetiva os estudantes desenvolvem com a escola e qual é o impacto que isso gera no desenvolvimento de cada um desses sujeitos.

No tocante à construção da escola enquanto instituição, o filosofo Jorge Larrosa (2018), citando Rancière (2003), explica que a escola não se define por uma função social externa. A escola separa o tempo e o espaço escolar de outros tempos e espaços sociais, definindo tipos especiais de espaço, tempo e ocupações. Isso é o que a diferencia de outras entidades ou instituições. Assim, segundo a antiguidade grega, a escola não seria um lugar de aprendizagem e sim de ócio. Ou seja, um lugar de tempo livre do trabalho para aprender.

Larrosa (2018, p. 234) chama a escola inventada pelos gregos de "filha da igualdade e do tempo livre", na perspectiva do autor, seria um lugar que apaga, pelo menos por pouco tempo, as desigualdades sociais. Lugar no qual as pessoas podem esquecer suas posições sociais e imaginar a possibilidade de ser qualquer coisa. No entanto, o autor salienta que o papel da escola e os conteúdos mudaram com o passar do tempo, pois a sociedade colonizou o ócio e mercantilizou o tempo livre.

Ainda conforme apontado por Larrosa (2018), no mundo antigo, a economia e a política serviam à escola e não o contrário, isso quer dizer que é a sociedade que deve servir à escola. Atualmente, vemos uma inversão desses papéis. A escola (ou universidade), muitas vezes, é usada para atender interesses econômicos e políticos de diferentes setores da sociedade, inclusive os da universidade. As diretrizes e parâmetros vêm de fora, e não o contrário, como acontecia na citada escola antiga. E talvez seja esse um dos pontos fundamentais de debate entre universidade, escola e comunidade: trazer de volta esse lugar onde a escola fala e é ouvida, e não apenas citada. É preciso dar à educação básica e seus professores o suporte e apoio necessários para que possam, como afirma Larrossa, "dizer à sociedade (aos políticos e economistas) o que é que eles têm que fazer para que a escola continue sendo escola" (LARROSA, 2018, p. 239).

Seguindo Biesta (2017), afirmamos que as instituições escolares devem tornar-se presença, através de cada profissional como sujeito único e singular que faz a sua parte, conforme o sujeito da educação apontado pelo autor, pois é por meio da subjetividade humana que o indivíduo se faz presente, mas é necessário buscar a essência humana onde cada pessoa se torna presença.

Ao encontrar tal essência, é possível des-professorizar, des-alunizar e des-disciplinar (LARROSA, 2018) a escola e a universidade, chegando mais perto da comunidade e fazendo do tempo livre do estudante um momento de aprender sem colonizar, respeitando os saberes locais, de acordo com cada sociedade.

Essa não é uma tarefa fácil, sobretudo porque também precisamos nos atentar aos obstáculos e à realidade do contexto educacional brasileiro, entre eles: a carga horária dos professores, falta de valorização profissional, a quantidade de alunos na sala de aula, os problemas curriculares e as lacunas didático-metodológicas, um dos assuntos que ganham destaque nas pesquisas acadêmicas.

3 Disponível em: https://www.youtube.com/watch?v=HX6P6P3x1Qg Acesso em: 20 de abril de 2020. 
Entretanto, dialogando em conjunto com outros setores, é possível fortalecer essas relações, fortalecer o lugar da escola e criar um movimento mais democrático, horizontal e transgressivo frente ao sucateamento da educação brasileira. Nessa perspectiva, apresentamos, a seguir, uma discussão acerca da relação entre a universidade e a escola.

\section{A relação entre uniVersidade e escola}

Hafernick et al (2002) pondera que o comportamento ético de um professor perpassa a humanidade, a justiça e o respeito. Nesse sentido, discorremos entre uma bidirecionalidade que diz, também, de um lugar comum, em direção à escola e à universidade como âmbitos formativos e em formação. Desse modo, as práticas colaborativas parecem incidir uma dialogicidade no que tange à redução da distância entre universidade e escola, caminhando em direção a um diálogo produtivo entre o ensino, a pesquisa e a extensão.

Salientamos, porém, que não existe uma "receita pronta" para construir uma relação entre o Ensino Superior e a Educação Básica, embora tenhamos vários aportes teóricos e relatos de experiências bem-sucedidos. Assim, antes de fazer esse diálogo com as pesquisas já publicadas e com nossas próprias experiências, é necessário destacar que o nome superior não deve inferiorizar o nome básico, levando em consideração o sentido decolonial dos saberes (MIGNOLO, 2018), bem como as discussões propostas por Telles (2002) e Mateus (2009). Logo, a pergunta que nos move é: "como conectar a escola, a universidade e a comunidade?". Para essa indagação, existe um pressuposto de que não há conexão. No entanto, ainda que essa "ponte" não tenha sido, de toda, estabelecida e que não seja o que esperávamos, ela existe.

Para Reis et al (2019), a relação entre as duas instituições (universidade e escola) deve ser de respeito e oportunidades, criando espaços de interação ao unir os saberes produzidos por ambos. Nesse sentido, vemos a necessidade de desmistificar a crença de que apenas a universidade produz conhecimento, cujo receptor é a educação básica. Na verdade, conforme defendido por Telles (2002), deve haver uma troca entre pesquisador e professor, para que este último possa obter instrumentos que lhe permitam desenvolver reflexões e ações de modo a melhorar seu trabalho em sala de aula.

Nesta perspectiva, o professor passa a ser agente e não mais sujeito. Passa a conhecer os objetivos e métodos da pesquisa, além de colaborar com o pesquisador na interpretação dos dados. O pesquisador, por sua vez, produz sentidos sobre as interpretações do professor, para construir quadros de significados.

Essa relação de igualdade entre escola e universidade é fundamental para responder à pergunta sobre como conectá-las. Usando a metáfora da Torre de Babel, Mateus (2009) afirma que as tensões entre teoria e prática distanciam ainda mais pesquisadores e professores, ensino superior e educação básica, conhecimento científico e conhecimento cotidiano, ou seja, o saber e o fazer. Esse distanciamento fica evidente por meio de trabalhos realizados sobre o outro e para o outro. Dessa maneira, o pesquisador coloca-se em posição privilegiada quando se trata da construção do conhecimento, destacando sua colonialidade, perpetuando a matriz colonial do poder e a totalidade eurocêntrica do conhecimento (MIGNOLO, 2018).

No que diz respeito à aprendizagem, Mateus (2009) enfatiza que é gerada com ação, diálogo e pensamento de todos os participantes, constituindo assim, um movimento criativo de transformação social dos sujeitos. A autora cita Bakhtin para explicar a relação dialética entre 
pesquisa e aprendizagem, nesse processo de diálogo com o outro: "a atividade crítico-praxiológica diz respeito à teoria que nasce da práxis e que retorna à práxis a fim de transformá-la de modo que faça sentido àqueles que dela participam" (MATEUS, 2009, p. 316).

A perspectiva dialética citada por Mateus (2009) está em consonância com Moita Lopes (1996), quando explica os caminhos das pesquisas em Linguística Aplicada, investigações que surgem da prática, passam pela teoria e retornam à prática, oferecendo, portanto, o retorno social. Tais caminhos que, por vezes, esquecemos de seguir. Assim, a atividade crítico-praxiológica destacada por Mateus (2009), refere-se ao processo dialético de ensino e pesquisa, de instrumento e resultado ou de aprendizagem e desenvolvimento.

E como pode ser feita essa conexão? Dentre as possibilidades estão os projetos de extensão que se desenvolvem dentro das universidades, como o Programa Institucional de Bolsas de Iniciação à Docência (PIBID). Compreender esses programas se torna relevante à medida que não há linguagem científica que descreva a vida social a partir daquilo que nomina uma visão cartesiana e determinista. Dessa forma, refletir e (re)construir a universidade e a escola, bem como a docência, a partir da (re)construção identitária de seus usuários- numa noção responsiva, ética e agente- desconsiderando as relações e o cerne da vida social que se manifesta em ambos polos, é tratar de uma realidade contextual de forma deweyana.

Nesse sentido, dirigimo-nos, finalmente, à segregação que fortalece fronteiras e incongruências que se refletem, inclusive, nas representações da docência, bem como na formação curricular que escapa à integralidade de uma universidade que conta com a licenciatura. Tratando de uma realidade prática, discorremos sobre movimentos que se manifestam em direção ao desenvolvimento de uma formação inicial e continuada que dialogue com a experiência escolar, já que não há conhecimento sem práxis e práxis sem conhecimento, como relatamos a seguir.

\section{Aproximando universidade e escola na UFMG}

Alguns dos relatos de experiência no contexto de universidade em parceria com a escola aqui apresentados são especificamente na área de língua espanhola. Tais projetos fizeram parte da vida acadêmica de uma das pesquisadoras que assina este texto, inserindo-a na dialogicidade entre teoria e prática.

Um dos projetos de extensão que pode facilitar a aproximação entre escola e universidade é o Programa Institucional de Bolsa de Iniciação à Docência, PIBID. Conforme aponta Sól (2019), o PIBID é um programa de formação no qual os alunos graduandos em licenciaturas unem teoria e prática, bem como renovam suas esperanças na profissão docente (SÓL, 2019).

Nesse sentido, destacamos o trabalho das professoras Elizabeth Guzzo de Almeida (FaE/ UFMG), Luiza Santana (CP/UFMG) e Sidnéia Nascimento (Escola Estadual Três Poderes), no PIBID Espanhol da UFMG. Ainda que as atividades do programa tenham encerrado em várias universidades, sucateando as iniciativas mínimas voltadas à sua permanência, diversos materiais didáticos surgiram em decorrência das atividades, como a coleção "Faz Espanhol: sequências didáticas de espanhol para crianças e adolescentes", a qual, a nosso ver, faz tornar o trabalho ainda vivo.

Assim, em meio à necessidade de subjetivação do "ser professor", como quem toma responsabilidade pelo seu trabalho, destacamos a significativa contribuição do PIBID como (des) construtor de representações acadêmicas sobre o significado da docência. O PIBID também 
contribuiu para a formação identitária dos futuros professores, além de providenciar tempo e ambiente seguro para que os graduandos pudessem descobrir suas práticas e testassem, de forma ética e embasada, novas formas de se ensinar.

Nesse sentido, Sól (2019) afirma que a importância do PIBID se justifica por trabalhar com a formação inicial e continuada de professores de línguas e por estreitar os laços entre o ensino superior e a educação básica, na medida que amplia as oportunidades de aprendizagem da docência, indo além dos estágios supervisionados obrigatórios.

Outro projeto importante nesse âmbito é o programa de Imersão Docente ou Pedagógica da UFMG, que promove ações integradoras da Política Nacional de Formação de Professores, visando ao desenvolvimento da formação em prática nos cursos de licenciatura, promovendo, ainda, a imersão do licenciando na escola de educação básica. Assim, contempla a experiência na área específica de ensino, acompanhado de um professor orientador. Dessa forma, o acadêmico tem a oportunidade de vivenciar as práticas escolares e extraescolares de uma escola integral que vem inserindo, continuamente, alunos de inclusão.

Desse modo, os bolsistas cedidos pela universidade, além de integrarem ações do Grupo de Trabalho Diferenciado (GTD) e ministrarem aulas sob supervisão de um professor experiente, podem manifestar apoio a outras atividades como a Educação de Jovens e Adultos (EJA) nos $\mathrm{PROEJA}^{4}$, e PIPA ${ }^{5}$. Uma mostra da formação inicial em sistema de colaboração e em contato entre teoria e prática.

Os programas de formação inicial desenvolvidos no Centro Pedagógico da UFMG objetivam uma noção formativa que se exercita de forma ativa a partir do fortalecimento e consolidação entre entidades formadoras, numa promoção de propostas pedagógicas que extrapolam a rede escolar, bem como a universidade.

No que tange à formação continuada, destacamos a criação do Programa de Residência Docente (PRD), inspirado na residência médica, como estratégia que resultou em outras medidas como a especialização em residência docente, destinada a professores da educação básica provenientes da rede municipal de ensino, cujo objetivo se pauta em promover o diálogo, tendo, como alicerce, a reflexão crítica de residentes/professores sobre sua ação docente no processo de ensino-aprendizagem de diferentes áreas epistemológicas. O curso contempla quatro semestres, desenvolvido a partir de módulos de conhecimentos específicos, bem como de coordenação e gestão pedagógico-administrativa.

Outro projeto que vale apena destacar é o FOCOELE (Projeto de Formação Continuada de Professores de Espanhol), promovido pela UFMG, sob coordenação da professora Elzimar Goettenauer de Marins Costa e do professor Cristiano Silva Barros, ambos docentes da Faculdade de Letras (FALE). O FOCOELE oferecia um curso semipresencial de formação continuada destinado a professores de espanhol como língua adicional. Segundo informações dispostas no endereço eletrônico do site, o projeto de Formação Continuada de Professores de Espanhol, criado em 2010, tem como objetivo a continuidade formativa, dando enfoque ao papel reflexivo das discussões e atividades realizadas.

Além de incidir sobre a formação crítica, o projeto também se pauta na construção de um espaço para a elaboração de compêndios didáticos, intercâmbio de experiências, leituras,

4 Programa Nacional de Integração da Educação Profissional com a Educação Básica na Modalidade de Educação de Jovens e Adultos

5 Programa de apoio à inclusão e à promoção de acessibilidade 
análises de materiais didáticos, pesquisas, desenvolvimento e uso de ferramentas digitais, desenvolvendo, finalmente, uma formação continuada com enfoque em atividades colaborativas. De acordo com Mateus (2009), é a aprendizagem gerada com ação, diálogo e pensamento de todos os participantes, por meio de um movimento criativo de transformação social dos sujeitos; sem diminuir nem supervalorizar nenhum saber.

Nesse sentido, programas e projetos que reforçam o lugar do professor de línguas como autônomo e responsável pelo seu próprio fazer docente são relevantes à medida que aproximam universidades e escolas como instituições que, ainda de diferentes polos, compartilham a mesma natureza transformativo-colaborativa. Contudo, tais práticas entre instituições podem ser desenvolvidas também na relação entre universidade e comunidade, como destacamos a seguir.

\section{RELAÇÃO UNIVERSIDADE-COMUNIDADE}

Temos acompanhado, através dos noticiários e outros veículos de comunicação, o grande projeto político de sucateamento da educação brasileira, sobretudo no que diz respeito ao ensino superior. Em maio de 2019, por exemplo, pudemos acompanhar uma série de manifestações em defesa da educação, uma vez que o Ministério da Educação havia anunciado um bloqueio nos recursos destinados para a educação. Recentemente, também pudemos observar o corte de centenas de bolsas de pós-graduação previstas para o começo do ano e que foram suspensas pela portaria 34, da Coordenação de Aperfeiçoamento de Pessoal de Nível Superior (CAPES), causando danos imensuráveis à pesquisa brasileira. Entretanto, pouco se fala no assunto.

Nesse contexto, a universidade segue isolada, sem apoio popular, mas ainda resiste. Uma parte daqueles que a constroem resistem no sentido de mobilização para continuar suas atividades nesse cenário obscuro e, infelizmente, grande parte ainda resiste no sentido de (não) abrir suas portas e derrubar seus muros para um diálogo real com a sociedade e com outros saberes - tão importantes quanto os produzidos dentro da universidade.

É preciso que a universidade, agora mais do que nunca, faça uma autocrítica e desça de seu pedestal para dialogar verdadeiramente com sociedade, escutar suas demandas e, colaborativamente com esses outros agentes, construir novos saberes e novas perspectivas. No mesmo caminho, é preciso que a universidade seja apropriada pela sociedade: negros, pobres, indígenas, (i)migrantes, refugiados, transexuais, travestis, homossexuais e outros grupos minorizados. Um dos passos para a entrada destes e de outros grupos para conhecer e se apropriar da universidade - que lhes é de direito - é a extensão.

A extensão universitária, nessa perspectiva, funciona como uma porta de entrada e uma das possibilidades desse diálogo com a sociedade, ao mesmo tempo em que, a partir de uma agenda bem elaborada, é capaz de unir ensino, pesquisa e extensão - tripé sobre o qual a universidade pública brasileira se ancora (ou deveria ancorar-se), já que, na prática, o tripé é manco.

Conforme apontam Cordeiro Mota e Andrade (2009) a tridimensionalidade ideal da educação superior, muitas vezes não acontece; seria aquela oportunidade para relacionar o conhecimento científico e o conhecimento cotidiano produzido por diferentes grupos sociais. Dessa forma, haveria um debate que estabeleceria um lugar para a universidade dentro da sociedade, um lugar no qual o conhecimento científico estaria em diálogo com as demandas sociais. Isto é, a relação universidade-comunidade que defendemos desde o início deste texto. 
Quando nos propomos a discutir a decolonização dos saberes, partimos da proposta do grupo Modernidade/Colonialidade, formado pela intelectual-militante Catherine Walsh, pelo sociólogo peruano Anibal Quijano, pelo antropólogo colombiano Arturo Escobar, pelo semiólogo argentino Walter Mignolo, pelo filósofo porto-riquenho Maldonado Torres e pelo seu colega também porto-riquenho e sociólogo Ramón Grosfoguel, dentre outros. Esses estudiosos dedicam-se a pensar as heranças da colonialidade em nossas formas de ser, estar, pensar, agir e se relacionar com/no mundo a partir do conceito de raça.

Quijano, desde 1989, defende uma categorização da Colonialidade do Poder, uma das discussões centrais do grupo. Tal categorização apresenta uma complexa configuração que, através de uma matriz colonial de poder, ampliada por Mignolo (MIGNOLO, 2018), cria uma representação de totalitarismo como espelho do mundo que desvaloriza qualquer outra forma de conhecimento que pudesse questionar ou desafiar essa relação dominante.

A estrutura da Matriz Colonial de Poder se relaciona através do controle de diferentes dimensões. Entre elas, a colonialidade do saber, cuja:

\begin{abstract}
elaboração intelectual do processo de modernidade produziu uma perspectiva de conhecimento e um modo de produzir conhecimento que demonstram o caráter do padrão mundial de poder: colonial/moderno, capitalista e eurocentrado. Essa perspectiva e modo concreto de produzir conhecimento se reconhecem como eurocentrismo. (QUIJANO, 2005, p. 9).
\end{abstract}

Decolonizar saberes, nessa perspectiva, significa, entre outros aspectos, ressignificar a construção do conhecimento em uma corrente contra hegemônica. Outras produções que dialogam diretamente com esse giro decolonial são as Ecologias do Sul (SOUSA SANTOS, 2010), uma vez que escutamos, aprendemos e buscamos dar credibilidade para os conhecimentos não científicos:

Trata-se, por um lado, de explorar concepções alternativas que estejam no interior do conhecimento científico e que tenham se tornado visíveis por meio de epistemologias pluralistas de diversas práticas científicas (em particular, as epistemologias feministas) e, por outro lado, de promover a interdependência entre os saberes científicos produzidos pela modernidade ocidental e saberes diferentes não científicos (SOUSA SANTOS, 2010, p. 225).

Nesse sentido, a proposta decolonial é, além de uma perspectiva, um diálogo com a escolha ancorada no pensamento crítico e que parte do Sul. O Sul, mencionado por Boaventura Sousa Santos não é o sul geográfico, mas os grupos que foram subalternizados pela Modernidade, invenção europeia criada não a partir do Iluminismo, mas com a descoberta da Abya Yala.

Nesse sentido, ressaltamos a importância e relevância dos saberes científicos produzidos nas universidades, mas reconhecemos, na mesma medida, a pluralidade de outros conhecimentos e experiências que se colocam de maneira alternativa à ciência moderna, enraizada na colonialidade do saber e do poder. Nessas relações outras, sobretudo pautadas a partir do Sul Global, o conhecimento é uma forma de resistência. Ao passo em quem temos ataques diretos às políticas públicas em suas mais variadas instâncias, para além da educação, as histórias locais (MIGNOLO, 2018) e os movimentos sociais passam a se (re)articular e (re)organizar em uma tentativa de impedir esses retrocessos. 
A ecologia de saberes proposta por Sousa Santos (2010), é uma forma de fortalecer esse diálogo em busca de um projeto epistêmico outro (MIGNOLO, 2018), em conjunto com práticas e saberes que são silenciados e apagados pela colonialidade. Na união entre os conhecimentos produzidos dentro e fora do ambiente acadêmico, em uma parceira horizontal e respeitosa, é possível posicionamento político de resistência e reexistência.

Este caminho, apesar de denso, é possível e já vem sendo feito através da extensão em várias instituições, por iniciativa de alguns professores. Para ilustrar o que temos discutido até aqui, nas próximas seções compartilhamos algumas das nossas experiências em atividades extensionistas que constroem esses diálogos entre universidade-escola e universidade-comunidade, de maneira mais horizontal e colaborativa.

\section{UNIÃO ENTRE UNIVERSIDADE-COMUNIDADE NA UNIFESP}

De acordo com o levantamento realizado pelo Alto Comissariado das Nações Unidas para Refugiados, em 2019, já existem mais de 70 milhões de deslocados forçados no mundo, dentre os quais 29,4 milhões estão em situação de refúgio. No Brasil, de acordo com o Comitê Nacional para Refugiados (2019) - também conhecido como CONARE - já foram aceitas 14.622 solicitações e 161 mil solicitações de refúgio ainda estão esperando por análise. O organismo público reconhece como refugiado todo aquele que:

\footnotetext{
Artigo $1^{\circ}$ - Será reconhecido como refugiado todo indivíduo que:

I - devido a fundados temores de perseguição por motivos de raça, religião, nacionalidade, grupo social ou opiniões políticas encontre-se fora de seu país de nacionalidade e não possa ou não queira acolher-se à proteção de tal país;

II - não tendo nacionalidade e estando fora do país onde antes teve sua residência habitual, não possa ou não queira regressar a ele, em função das circunstâncias descritas no inciso anterior;

III - devido a grave e generalizada violação de direitos humanos, é obrigado a deixar seu país de nacionalidade para buscar refúgio em outro país (BRASIL, 1997, Lei nº 9.474, $\left.\operatorname{artigo} 1^{\circ}\right)$.
}

Nesse sentido, muitas organizações não governamentais e instituições religiosas, conforme apontam Amado (2013) e Lopez (2016) têm assumido o papel de acolhimento dessas pessoas e auxiliado com diferentes demandas, como a regularização de documentos, inserção laboral, assistência médica, busca por moradia e ensino de língua.

A partir da experiência na Ong Oásis Solidário, localizada no bairro do Pari, um grupo de estudantes da Universidade Federal de São Paulo (UNIFESP) decidiu levar à universidade a proposta de dialogar com esse público e assumir a demanda do ensino de língua portuguesa. Nesse sentido, fundado em 2015, como projeto cultural apoiado pela Pró Reitoria de Assuntos Estudantis, o MemoRef é uma iniciativa de estudantes do curso de Letras da Universidade Federal de São Paulo e refere-se a um conjunto de ações, culturais e educativas, de referência social que tem como objetivo contribuir com o processo de integração de pessoas em situação de refúgio na sociedade brasileira. Atualmente, a ação é reconhecida como um dos projetos de extensão da UNIFESP e coordenado em conjunto pela Profa. Dra. Hosana dos Santos Silva e pela discente Cristina Conceição Xavier. 
Para atingir tal objetivo, o projeto foi concebido em três vertentes: ensino de Português como Língua de Acolhimento ${ }^{6}$, oficinas culturais nas quais os próprios alunos atendidos pelo projeto atuavam como oficineiros e a criação de uma espécie de Museu Digital com histórias e relatos de vida dos nossos alunos. Essas três atividades principais, nesse sentido, são capazes de criar espaços de diálogo entre a universidade e sociedade, escola e universidade (através de palestras, rodas de conversa e do próprio memorial digital) e entre os próprios agentes que compõe a comunidade acadêmica.

Outras ações, em diferentes instâncias e localidades da UNIFESP também contribuíram com a discussão sobre imigração e refúgio dentro do espaço acadêmico. Entre elas, podemos destacar o Curso de Aperfeiçoamento sobre Saúde Mental, Imigração e Interculturalidade, coordenado pelas professoras Sylvia Dantas e Débora Galvani em parceria com docentes de diferentes campi da UNIFESP, a Cátedra Sérgio Vieira de Melo coordenada pelo professor João Alberto Alves Amorim, o curso de Português para Imigrantes proposto pelo Laboratório de Investigação em Migração, Nação e Fronteira (LIMINAR), sob a coordenação do professor Lindomar Coelho Albuquerque, a gestão da UNIFESP e a Capacitação de professores de língua portuguesa em situação de refúgio, coordenada pela professora Hosana dos Santos Silva.

Tais iniciativas, que dialogam com movimentos sociais, organizações não governamentais e outras instâncias contribuíram, de certa forma, com um outro olhar da Universidade para essas demandas. Como conquista dessas ações, podemos, atualmente, comemorar o primeiro edital especial para o ingresso de pessoas refugiados, apátridas e portadores de visto humanitário na Universidade Federal de São Paulo, realizado no primeiro semestre de 2020, dos quais 29 inscritos foram aprovados e 14 convocados para matrícula ${ }^{7}$. Essa notícia, assim como a aprovação das cotas raciais no acesso ao ensino superior, são respostas positivas e ações que produzem rachaduras na colonialidade do poder, conforme discutido amplamente pelo grupo Modernidade/ Colonialidade e outros estudiosos que se apoiam na perspectiva dos estudos decoloniais.

\section{Projeto de extensão da UERR}

No mesmo sistema de valorização da extensão universitária, os professores do curso de Letras da Universidade Estadual de Roraima implantaram o Projeto Português para Estrangeiros, no campus de Pacaraima, na fronteira com a Venezuela. Era um curso de português destinado aos estrangeiros moradores da região fronteiriça que teve início em 2010, a partir da demanda social daquela população. Para os acadêmicos de letras, por sua vez, foi uma atividade complementar e até de estágio supervisionado para a formação inicial.

Conforme afirma Sól (2019), os projetos de extensão conseguem ir além dos estágios supervisionados regulares, tal como foi evidenciado no projeto da fronteira, pois se transformou em uma oportunidade para unir o ensino, a pesquisa e a extensão. Todas as atividades eram planejadas entre acadêmicos monitores e professores coordenadores, após capacitações e dis-

6 O termo língua de acolhimento parte do programa "Portugal Acolhe" (2001) criado pelo Ministério do Trabalho de Portugal com o intuito de integrar imigrantes recém-chegados ao país. No Brasil, os estudos se concentram no ensino de língua portuguesa para pessoas em situação de refúgio e outros grupos minorizados. A partir da proposta de Amado (2013) e Lopez \& Diniz (2018), é possível entender que o ensino no âmbito dos estudos de Português Língua de Acolhimento se dá de maneira transdisciplinar, no diálogo com outros saberes, cujas práticas, sempre crítico-reflexivas, podem contribuir para o agenciamento e empoderamento (MAHER, 2007) de seus alunos, de forma que, ao se deparar com determinadas situações - inclusive as mais vulneráveis - possam, em alguma medida, agir de forma autônoma, consciente e politicamente fortes (REINOLDES, 2019).

$7 \mathrm{https}$ ///www.unifesp.br/reitoria/prograd/servicos-menu/servicos-da-graduacao/noticias-sub-servicos/775-2020-resultado-processo-seletivo-refugiados-apatridas-e-portadores-de-visto-humanitario 
cussões teóricas relacionas ao ensino de português para estrangeiros, levando em consideração a perspectiva intercultural. Muitos dos discentes participantes do projeto eram voluntários e seguiram do ensino para a extensão, até chegarem à pesquisa, com trabalhos de conclusão de curso cujas pesquisas de campo destacaram diversos aspectos do projeto.

Outro ponto importante foi o elo entre a universidade e a comunidade, não apenas o público alvo do projeto (os estrangeiros moradores da região), mas a comunidade da pequena cidade de Pacaraima e de comunidades indígenas do munícipio ${ }^{8}$. Além das aulas regulares que aconteciam todos os sábados, das 8:00 às 12:00, o projeto realizava diversas atividades abertas ao público em geral, como: sarau literário em locais públicos, eventos esportivos, apresentações culturais em escolas e visitas de campo a comunidades indígenas.

Alencar (2019) mostrou como o Projeto de Extensão Português para Estrangeiros colaborou com a integração cultural na fronteira Brasil/Venezuela, através das diversas atividades realizadas em Pacaraima. Conforme o autor:

Por fim, percebo mais uma vez o foco do Campus Pacaraima da UERR na fronteira e as iniciativas para fortalecer a integração e os processos de cooperação da comunidade. Estas trocas culturais que realiza são o cimento do bom convívio entre dois povos. Além disso, notável é a função social das Universidades públicas, especialmente em regiões de fronteira, como foi possível perceber no caso da UERR (ALENCAR, 2019, p. 79).

No trecho acima o autor destaca o papel social da universidade pública no sentido de promover a integração e a cooperação da comunidade, em especial na região fronteiriça. No entanto, o Português para Estrangeiros era mais do que integração, era ser presença (BIESTA, 2017); eram momentos de compartilhar saberes, no sentido decolonial (MIGNOLO, 2018), saindo da esfera acadêmica para valorizar os saberes culturais da região.

Em uma atividade de final de ano, acadêmicos monitores e estudantes de português decidiram "levar alegria a uma comunidade indígena da região", organizaram brincadeiras, conseguiram doações de brinquedos para as crianças, levaram comidas e bebidas. Após passar o dia inteiro em interação com as pessoas da comunidade, os estudantes (de graduação e do curso de extensão) descobriram que receberam muito mais do que doaram. Ao compartilhar a experiência em sala de aula, sentiram-se gratos pela oportunidade de aprendizagem na comunidade indígena, que foi além da questão linguística e cultural. Os registros fotográficos e em vídeo mostraram o laço possibilitado pela união da universidade com a comunidade, que só foi possível através da extensão. À equipe do projeto, nos permitiu aprender que ninguém está em situação privilegiada quando se trata de conhecimento.

\section{CONSIDERAÇÕes FINAIS}

Com o destaque dos programas discorridos, nota-se a premência de ações dialógicas que relacionem às representações do "ser docente", reagindo a transições em estruturas sociais que apontam para o sucateamento de ações como o PIBID e o FOCOELE. Num comprometimento de prosseguir junto às novas práticas de usos linguísticos, novas formas de aprender e responder, de forma profícua, a uma sociedade polarizada, a qual evidencia o alarme de um movimento reflexivo e do "pensar" como ação filosófica e (in) disciplinar, é relevante encontrar meios de

8 O munícipio de Pacaraima está localizado em duas Terras Indígenas homologadas, São Marcos e Raposa Serra do Sol, a única área urbana não indígena é a sede municipal, na qual estão localizadas todas as instituições. 
garantir a formação docente - inicial e continuada- significativa que dialogue com o lugar mais social do ser presença (BIESTA, 2017): a escola pública.

É preciso buscar um outro olhar para a Universidade e suas relações, seja com a escola, seja com a sociedade. Dessa forma, devemos repensar o que entendemos por responsabilização e sobre qual o lugar que ocupamos nessas instituições. Partindo do "ser responsável" pela construção da Universidade e da Escola e pela decolonização de saberes do próprio "modus operandi" do âmbito universitário, ao compreender que é preciso cautela para refletir - em nosso próprio discurso- sobre essas relações, ainda que seja preciso valorizar e reconhecer as então travessias até aqui: as perguntas sempre irão existir e as respostas fazem parte de um processo subjetivo, relativo e transitório.

Acreditamos que considerar uma razão teórica como movimento que prescinde da prática (aprofundando-a), bem como partir da razão prática que ressignifica essa teoria, seria dirigir-se à noção de dialogicidade num movimento exotópico e de alteridade que caminha para a (re) construção de uma universidade como agência, que resiste e (re)existe com a escola e com a sociedade.

\section{RESIST IN (RE) EXISTENCE: DECOLONIZING KNOWLEDGE IN THE UNIVERSITY-SCHOOL-COMMUNITY RELATIONSHIP}

ABSTRACT: The aim of this text is to problematize the university-school-community relationship, encouraging the development of the professional and human potential of students and teachers in the three pillars: teaching, research and extension. From such bias, we also highlight the dialogical (CALVO AND FREITAS, 2011) and the decolonial relationship of knowledge (MIGNOLO, 2013; QUIJANO, 2005) of all the entities involved with a qualitative and interpretative approach, through bibliographic research and experience reports from researchers at three higher education institutions: UFMG, UNIFESP, and UERR. The discussions guide us towards a transformation of the subject of education focused on being present, according to Biesta (2017). Thus, we emphasize the theoretical view as a movement that dispenses with practice, whose practice resignifies theory, through the notion of dialogic that leads to the (re) construction of a university as an agency, which resists and (re) exists with the school and the society.

Keywords: Teaching-research-extension. Dialogicity. Decoloniality. (Re)existence.

\section{REFERENCIAS}

ALENCAR, G. Z. Os eventos artísticos culturais transfronteiriços: cooperação e solidariedade na fronteira. Dissertação (mestrado) - Universidade Federal de Roraima, Programa de Pós-Graduação em Sociedade e Fronteira. Boa Vista, 2019. Disponível em: file:///C:/Users/Cora\%20Elena/Downloads/ dissertao\%20de $\% 20$ mestrado $\% 20-\% 20$ gabriel $\% 20$ de $\% 20$ souza $\% 20$ alencar.pdf. Acesso em 28 de maio 2020.

ALTO COMISSARIADO DAS NAÇÕES UNIDAS PARA REFUGIADOS (ACNUR).

Dados sobre refúgio no Brasil. Em: https://www.acnur.org/portugues/dados-sobre-refugio/dadossobre-refugio-no-brasil/. Acesso em: 05 jul. 2019.

AMADO, R.S. O ensino de português como língua de acolhimento para refugiados. Revista da SIPLE, Brasília, ano 4, n. 2, outubro de 2013. Em: https://75594e48-8adc-4b90-bea7-68134515f6e2.filesusr. com/ugd/aa72b0 9aeb1cd15ab547df801c509e7978e193.pdf. Acesso em: 10 mai. 2019.

ARRIADA, E.; NOGUEIRA, G.M.; VAHL, M. M. A sala de aula do século XIX: disciplina, controle e organização. CONJECTURA: filosofia e educação, v. 17, n. 2, p. 37-54, 2012.

BORTONI-RICARDO, S. M. O professor pesquisador: introdução à pesquisa qualitativa - São Paulo: Parábola Editorial, 2008. 
CORDEIRO MOTA, F. M. G. S.; ANDRADE, F. C. B. Ensino, pesquisa e extensão: um exercício de indissociabilidade na pós-graduação. Revista Brasileira de Educação, v. 14, n. 41, maio/ago., 2009. Disponível em: https://www.scielo.br/pdf/rbedu/v14n41/v14n41a06.pdf. Acesso em 20 de maio 2020. HAFERNICK, J.J., MESSERSCHMITT, D.S. \& VANDRICK, S. Ethical Issues for ESL Faculty. Social Justice in Practice. Lawrence Erlbaum Associates, 2002.

KLEIMAN, A. B. A agenda de pesquisa e ação em Linguística Aplicada: problematizações. In: MOITA LOPES, L. P. M. (org.). Linguística Aplicada na modernidade recente. Festchrift para Antonieta Celani. São Paulo: Parábola editorial, 2013.

LARROSA, J. Da Dificuldade da Escola. In. LARROSA, J. Esperando não se sabe o quê: sobre o ofício do professor. Trad. Cristina Antunes. 1 ed. Belo Horizonte: Autêntica Ed., 2018. p. 229-260.

LARROSA, J. Fim de partida. Ler, escrever, conversar (e talvez pensar) em uma faculdade de educação. In. LARROSA, J. Tremores: escritos sobre experiência. Trad. Cristina Antunes e João Wanderley Geraldi. 1 ed. 3 reimpressão. Belo Horizonte: Autêntica Ed., 2018. p. 123-174.

MAHER, T. M. A educação do entorno para a interculturalidade e o plurilinguismo. In: KLEIMAN, A. B.; CAVALCANTI, M. C. (Orgs.) Linguística Aplicada: suas faces e interfaces. Campinas, SP: Mercado de Letras, 2007, p. 255-270.

MOITA LOPES, L. P. (org.). Por uma linguística aplicada indisciplinar. São Paulo: Parábola, 2006.

MATEUS, E. Torres de Babel e línguas de fogo: um pouco sobre pesquisas na formação de professores de inglês. Revista Brasileira de Linguística Aplicada, v.9, n. 1, 2009, p.307-328.

MIGNOLO, W. Eurocentrism and coloniality: the question of de totality of knowledge. In: MIGNOLO, W; WALSH, C. On decoloniality: concepts, analytic, praxis. Durham: Duke University Press, 2018, p.194-210.

PENNYCOOK A. Uma linguística aplicada transgressiva. In: MOITA LOPES, L. P. (org.). Por uma linguística aplicada indisciplinar. São Paulo: Parábola, 2006, p. 67-84.

QUIJANO, A. Colonialidad del poder y clasificación social. Buenos Aires: CLACSO, 2014. Disponível em: http://biblioteca.clacso.edu.ar/clacso/se/20140506032333/eje1-7.pdf Acesso em: 20 mai. 2020

Colonialidade do poder, Eurocentrismo e América Latina. Buenos Aires: CLACSO, 2005. Disponível em: http://biblioteca.clacso.edu.ar/clacso/sur-sur/20100624103322/12 Quijano.pdf Acesso em: 20 mai. 2019.

REIS, V. S.; SOL. V. S. A; CARVALHO, F. P.; GONÇALVEZ, I. L.; FERREIRA, L. P. M.; (Re) construindo saberes, fazeres e parcerias para a sala de aula de língua estrangeira. In: FINARDI, K. R.; SCHERRE, M. M; TESCH,L. M; CARVALHO, H. M. A Diversidade de fazeres em torno da linguagem: universidades, faculdades e educação básica em ação. Campinas, SP: Pontes, 2019.

SÓL, V. S.A. PIBID de Letras-Inglês: a importância da colaboração escola-universidade para a formação inicial-continuada de professores. In: SOUZA, G. P.; PRAZERES, L. A.; NOGUEIRA, M. O.; SÓL, V. S. A. (Orgs). PIBID UFOP em diálogo com a educação básica: percursos para a formação de professores. Curitiba: CRV, 2019. 166 p., 17-34.

REINOLDES, M. Falam de nós, mas não nos dão a palavra: cocriando orientações para práticas pedagógicas em Português como Língua de Acolhimento. Projeto de Pesquisa aprovado pelo Programa de Pós Graduação em Estudos Linguísticos da Faculdade de Letras, Universidade Federal de Minas Gerais, Belo Horizonte, 2020.

SOUSA SANTOS, B. S. Para além do pensamento abissal: das linhas globais a uma ecologia de saberes. In: SANTOS, B. S. \& MENEZES, M. P. M. Epistemologias do sul. Portugal. Ed.Cortez, 2010.

TELLES, J. A. É pesquisa é? Ah, não quero não, bem! Sobre pesquisa acadêmica e sua relação com a prática do professor de línguas. Linguagem \& Ensino, v.5, n.2, p.91-116, 2002. Disponível em: https:// periodicos.ufpel.edu.br/ojs2/index.php/rle/article/viewFile/15560/9747. Acesso em: setembro de 2019. 